\title{
Preemptive antiviral therapy with entecavir can reduce acute deterioration of hepatic function following transarterial chemoembolization
}

\author{
Sun Hong Yoo', Jeong Won Jang ${ }^{2}$, Jung Hyun Kwon², Seung Min Jung² ${ }^{2}$ Bohyun Jang ${ }^{2}$, and Jong Young Choi ${ }^{2}$ \\ ${ }^{1}$ Department of Internal Medicine, Bundang Jesaeng Hospital, Seongnam; ${ }^{2}$ Department of Internal Medicine, College of Medicine, The \\ Catholic University of Korea, Seoul, Korea
}

Background/Aims: Hepatic damage during transarterial chemoembolization (TACE) is a critical complication in patients with hepatitis B virus (HBV)-related hepatocellular carcinoma (HCC). Apart from its role in preventing HBV reactivation, there is some evidence for the benefits of preemptive antiviral therapy in TACE. This study evaluated the effect of preemptive antiviral therapy on acute hepatic deterioration following TACE.

Methods: This retrospective observational study included a prospectively collected cohort of 108 patients with HBVrelated HCC who underwent TACE between January 2007 and January 2013. Acute hepatic deterioration following TACE was evaluated. Treatment-related hepatic decompensation was defined as newly developed encephalopathy, ascites, variceal bleeding, elevation of the bilirubin level, prolongation of prothrombin time, or elevation of the Child-Pugh score by $\geq 2$ within 2 weeks following TACE. Univariate and multivariate analyses were conducted to identify factors influencing treatment-related decompensation. Preemptive antiviral therapy involves directing prophylaxis only toward high-risk chronic hepatitis B patients in an attempt to prevent the progression of liver disease. We regarded at least 6 months as a significant duration of preemptive antiviral treatment before diagnosis of HCC.

Results: Of the 108 patients, 30 (27.8\%) patients received preemptive antiviral therapy. Treatment-related decompensation was observed in 25 (23.1\%) patients during the follow-up period. Treatment-related decompensation following TACE was observed more frequently in the nonpreemptive group than in the preemptive group ( $29.5 \%$ vs. $6.7 \%, P=0.008)$. In the multivariate analysis, higher serum total bilirubin (Hazard ratio $[\mathrm{HR}]=3.425, P=0.013$ ), hypoalbuminemia (HR=3.990, $P=0.015)$, and absence of antiviral therapy $(\mathrm{HR}=7.597, P=0.006)$ were significantly associated with treatment-related hepatic decompensation.

Conclusions: Our findings suggest that preemptive antiviral therapy significantly reduces the risk of acute hepatic deterioration. Preventing hepatic deterioration during TACE by applying such a preemptive approach may facilitate the continuation of anticancer therapy and thus improve long-term outcomes. (Clin Mol Hepatol 2016;22:458-465)

Keywords: Acute hepatic decompensation; Chronic hepatitis B; Hepatocellular carcinoma; Transarterial chemoembolization; Preemptive antiviral treatment

\footnotetext{
Abbreviations:

AASLD, American Association for the Study of Liver Diseases; ALT, alanine aminotransferase; AST, aspartate aminotransferase; AFP, alpha-fetoprotein; BCLC Barcelona Clinic Liver Cancer; CTC, common terminology criteria; HBV, hepatitis $B$ virus; $H C C$, hepatocellular carcinoma; $H R$, hazard ratio; $S D$, standard deviation; TACE, transarterial chemoembolization; HBeAg, hepatitis B envelope antigen
}

\section{Corresponding author : Jeong Won Jang}

Department of Internal Medicine, The Catholic University of Korea, Seoul ST. Mary's Hospital, 222 Banpo-daero, Seocho-gu, Seoul 06591, Korea

Tel: +82-2-2258-6015, Fax: +82-2-3481-4025

E-mail: garden@catholic.ac.kr 


\section{INTRODUCTION}

Hepatocellular carcinoma (HCC) is the fifth most common cancer in the world and the most common primary liver cancer. ${ }^{1}$ There are a variety of therapies for treatment of HCC; among them, transarterial chemoembolization (TACE) is one of the most commonly used treatment modalities. ${ }^{2}$ TACE induces ischemic tumor necrosis by obstruction of hepatic artery blood flow and exerts an anticancer effect via chemotherapeutic agents such as adriamycin or cisplatin mixed with Lipiodol. In the American Association for the Study of Liver Diseases (AASLD) guidelines for the management of HCC, TACE is recommended for patients with intermediate-stage HCC according to the Barcelona Clinic Liver Cancer (BCLC) staging system, because TACE was found to improve survival compared with the best supportive care in patients with unresectable $\mathrm{HCC}^{3-5}$ Although TACE is the established standard of care only for intermediate-stage HCC, in recent years, TACE has been used widely even in treatment of advanced-stage $\mathrm{HCC}^{6-9}$ The most frequent side effects of TACE are fever, nausea, and abdominal pain, and these side effects are self-limiting in the majority of patients. However, acute deterioration of hepatic function following TACE is a potentially life-threatening complication that occasionally interferes with continuation of TACE in patients with HCC. ${ }^{10}$ Although TACE has marked direct antitumor effects, it can also result in more complications than conservative management, because the ischemic damage caused by TACE can influence not only tumor tissue but non-tumorous liver tissue.

Antiviral therapy against hepatitis B virus (HBV) is known to reduce the incidence of hepatic decompensation and delay clinical progression in patients with advanced fibrosis or cirrhosis. ${ }^{11}$ In particular, entecavir, one of the nucleot(s)ide analogues, is a potent inhibitor of HBV replication. It is known that preemptive antiviral therapy prevents the reactivation of HBV in patients undergoing TACE. ${ }^{12-14}$ Apart from its role in preventing HBV reactivation, there are limited data on the benefits of preemptive antiviral therapy in deterioration of hepatic function related to TACE. This study aimed to evaluate the effect of preemptive antiviral therapy with entecavir on acute deterioration of hepatic function following TACE.

\section{MATERIAL AND METHODS}

\section{Study population}

This is a retrospective observational study of 108 patients in a prospectively collected cohort with HBV-related HCC who underwent TACE at the Catholic university of Korea Incheon St. Mary's hospital between January 2007 and January 2013 (Fig. 1). Primary HCC was diagnosed in 561 patients in our institution. Patients who met the following criteria were entered into the study: age $\geq$ 18 years; hepatitis $B$ surface antigen positive for at least 6 months; Child-Pugh Class A or B status; Barcelona Clinic Liver Cancer stage 0 , A, or B HCC; treated with TACE; and antiviral therapy using entecavir $0.5 \mathrm{mg}$ or no antiviral therapy. Patients were excluded for the following reasons: the presence of other liver diseases, including chronic hepatitis C, alcoholic liver disease, or autoimmune hepatitis $(n=199)$; Child-Pugh class $C$ status $(n=43)$; BCLC stage C or D ( $n=137)$; other treatment for HCC including surgery, radiofrequency ablation, percutaneous ethanol injection, liver transplantation, or radiotherapy $(n=50)$; mutation of HBV $(n=3)$; or other antiviral therapy $(n=21)$. Therefore, the

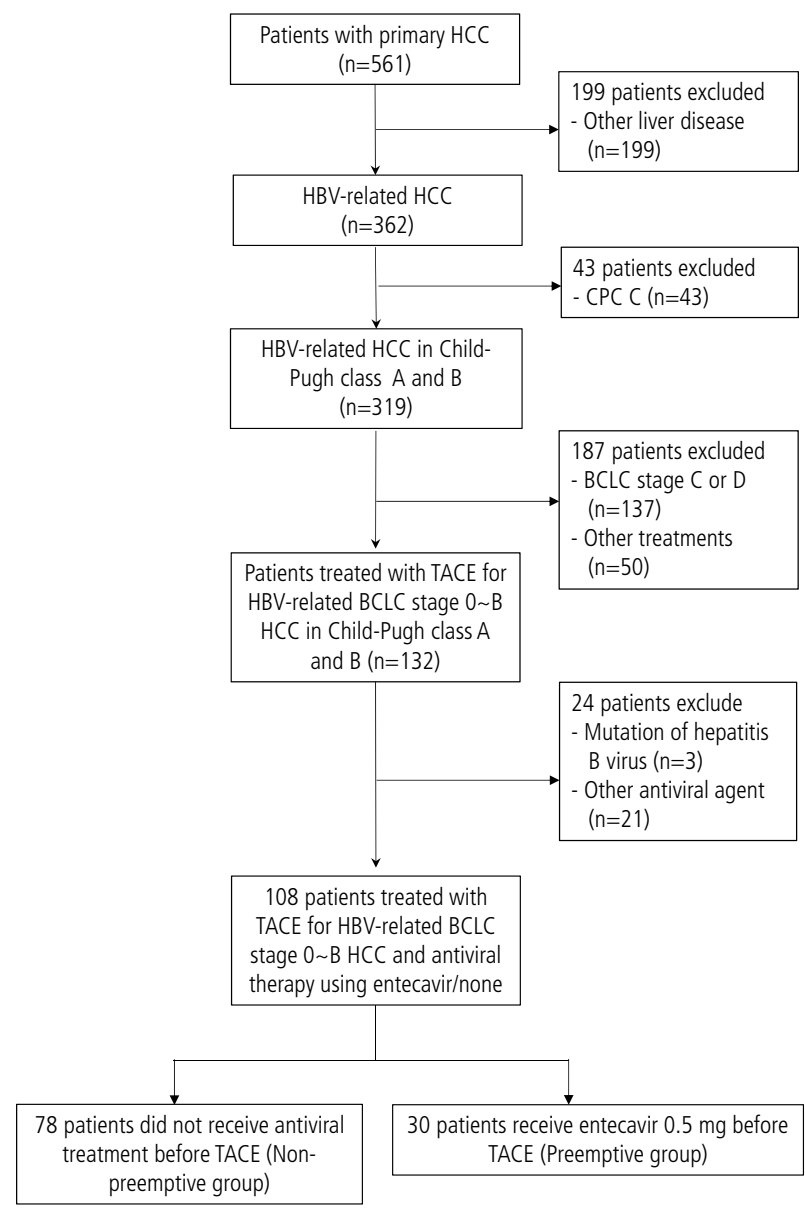

Figure 1. Flow diagram of patient enrollment. HCC, hepatocellular carcinoma; CPC, child-pugh class; BCLC, barcelona clinic liver cancer; TACE, transarterial chemoembolization. 
study cohort consisted of 108 patients treated with TACE for HBVrelated $B C L C$ stage $0-B$ HCC, of whom 30 were given entecavir $0.5 \mathrm{mg}$ prior to TACE. The diagnosis of HCC was done on the basis of the AASLD practice guidelines. ${ }^{3}$ The initiation of antiviral therapy was generally based on the Korean Association for the Study of the Liver guidelines ${ }^{15}$ and the Korean national insurance policy: HBV DNA $\geq 2,000 \mathrm{IU} / \mathrm{mL}$ and serum aminotransferase level above upper limit normal. We regarded at least 6 months as a significant duration of preemptive antiviral treatment before diagnosis of HCC. This study was approved by the local ethical committee and Institutional Review Board of the Catholic University of Korea.

\section{TACE procedure and follow-up}

TACE was performed by injection of doxorubicin hydrochloride (50 mg/session) and iodized oil (Lipiodol Ultra Fluid; Guerbet, France). After the first TACE session, follow-up TACE sessions were performed every 2 months until CT scans suggested complete tumor remission and TACE showed no more hypervascular staining of the tumor. After TACE, liver and renal function tests, including albumin, total bilirubin, aspartate transaminase, alanine transaminase, prothrombin time-international normalized ratio, and creatinine levels were monitored at least every 3 days. CT scans were performed every 2 months to evaluate treatment response and progression of liver cirrhosis.

Table 1. Baseline characteristics of the study population

\begin{tabular}{|c|c|c|c|c|}
\hline Characteristics & $\begin{array}{c}\text { Total } \\
(n=108)\end{array}$ & $\begin{array}{l}\text { Preemptive group } \\
\qquad(n=30)\end{array}$ & $\begin{array}{l}\text { Non-preemtive group } \\
\qquad(n=78)\end{array}$ & $P$-value \\
\hline \multicolumn{5}{|l|}{ Gender (n, \%) } \\
\hline Male & $84(77.8)$ & $25(83.3)$ & $59(75.6)$ & \\
\hline Female & $24(22.2)$ & $5(16.7)$ & $19(24.4)$ & 0.45 \\
\hline Age (Years) & $57.6 \pm 9.6$ & $60.3 \pm 7.9$ & $56.7 \pm 10.1$ & 0.120 \\
\hline \multicolumn{5}{|l|}{ HBeAg $(n, \%)$} \\
\hline Positive & $40(37.0)$ & $14(46.7)$ & $26(33.3)$ & \\
\hline Negative & $68(63.0)$ & $16(53.3)$ & $52(66.7)$ & 0.266 \\
\hline HBV DNA (copies/mL) & $3.2 \times 10^{5}\left(56-2.7 \times 10^{8}\right)$ & $7.6 \times 10^{5}\left(56-2.7 \times 10^{8}\right)$ & $6.7 \times 10^{4}\left(56-1.0 \times 10^{8}\right)$ & 0.100 \\
\hline \multicolumn{5}{|l|}{ Child-Pugh class (n, \%) } \\
\hline A & $84(77.8)$ & $22(73.3)$ & $62(79.5)$ & \\
\hline B & $24(22.2)$ & $8(26.7)$ & $16(20.5)$ & 0.492 \\
\hline Total bilirubin (mg/dL) & $0.85(0.2-3.1)$ & $1.15(0.4-2.9)$ & $0.80(0.2-3.1)$ & 0.359 \\
\hline $\operatorname{ALT}(I U / L)$ & $48.5 \pm 41.9$ & $56.4 \pm 51.1$ & $45.5 \pm 38.2$ & 0.226 \\
\hline Albumin (g/dL) & $3.75 \pm 0.55$ & $3.6 \pm 0.6$ & $3.8 \pm 0.5$ & 0.036 \\
\hline Creatinine (mg/dL) & $1.00 \pm 1.22$ & $1.0 \pm 1.4$ & $1.0 \pm 1.2$ & 0.957 \\
\hline Platelet $\left(\times 10^{3} / \mathrm{mm}^{3}\right)$ & $127 \pm 64$ & $102 \pm 58$ & $136 \pm 64$ & 0.008 \\
\hline PT INR & $1.16 \pm 0.15$ & $1.23 \pm 0.16$ & $1.13 \pm 0.15$ & 0.008 \\
\hline $\operatorname{AFP}(n g / m l)$ & $23.25(1.59-318600.00)$ & $18.59(2.28-157570.00)$ & $23.26(1.59-318600.00)$ & 0.801 \\
\hline Total tumor size (cm) & $5.7 \pm 4.8$ & $6.2 \pm 5.6$ & $5.5 \pm 4.6$ & 0.527 \\
\hline \multicolumn{5}{|l|}{ BCLC stage $(n, \%)$} \\
\hline 0 & $23(21.3)$ & $7(23.3)$ & $16(20.5)$ & \\
\hline$A$ & $45(41.7)$ & $12(40.0)$ & $33(42.3)$ & 0.743 \\
\hline$B$ & $40(37.0)$ & $11(36.7)$ & $29(37.2)$ & 0.804 \\
\hline
\end{tabular}

The $\chi^{2}$ test for categorical variables and Student's $t$ test for continuous variables. Data are presented as the mean \pm standard deviation, median (range in parentheses) or number of patients (percentages in parentheses).

HBeAg, hepatitis B envelope antigen; HBV DNA, hepatitis B virus deoxyribonucleic acid; ALT, alanine aminotransferase; PT INR, prothrombin time international normalized ratio; AFP, alpha-fetoprotein; BCLC, Barcelona Clinic Liver Cancer. 


\section{Assessment of outcomes}

The primary endpoint was development of treatment-related deterioration of hepatic function after TACE for HBV-related HCC. Secondary endpoints included development of HBV reactivation, hepatitis, severe hepatitis, or $\geq$ grade 3 common toxicity criteria of hepatic measures, including alanine aminotransferase, aspartate aminotransferase, and blood bilirubin. Acute deterioration of hepatic function was defined as newly developed encephalopathy, ascites, variceal bleeding, hepatorenal syndrome, a bilirubin level more than 2.5 times the upper normal limit, prolongation of prothrombin time by more than 3 seconds, or an elevation of the Child-Pugh score $(\geq 2)$ within 2 weeks following TACE. 10,16,17 HBV reactivation was defined as a greater than 10 -fold increase in serum HBV DNA from nadir during antiviral therapy. Hepatitis and severe hepatitis were defined as AST or ALT scores that were more than 2 times and 5 times the upper normal limits, respectively. Hepatic common toxicity criteria were based upon the common terminology criteria (CTC) for adverse events version 4.0. ${ }^{18}$

\section{Statistical analyses}

Categorical variables are described as frequencies and percentages. Continuous variables are presented as means \pm standard deviations (SD) and medians with interquartile ranges for parametric and non-parametric variables, respectively. Baseline characteristics were analyzed using the $\chi 2$ test for categorical variables and Stu- dent's $t$ test for continuous variables. Cox proportional hazards models were used to assess the risk factors for treatment-related decompensation after TACE. The variables used for multivariate analysis were selected on the basis of statistical significance in the univariate analysis $(P<0.10)$. Multivariate analysis was performed using a forward conditional stepwise procedure to exclude confounding variables. Kaplan-Meier curves and a log-rank test were used to estimate the cumulative incidence of treatment-related decompensation. A $P$-value less than 0.05 on a two-tailed test was regarded as statistically significant. Statistical analyses were carried out using the Statistical Package for the Social Sciences version 16.0 for Windows (SPSS, Inc., Chicago, IL, USA).

\section{RESULTS}

\section{Characteristics of the study population}

The clinical characteristics of the patients at the time of diagnosis of HCC are shown in Table 1. The study population was comprised of 108 patients who met the eligibility criteria, 30 of whom received antiviral therapy (preemptive group; entecavir $0.5 \mathrm{mg}$ ) and 78 of whom did not receive antiviral therapy (non-preemptive group) prior to TACE. The mean age of the 108 patients was 57.6 years (SD: 9.6 years), and 84 (77.8\%) were male. In baseline liver function, 84 patients (77.8\%) were Child-Pugh class A and 24 patients (22.2\%) were class B. Regarding tumor characteristics, 23

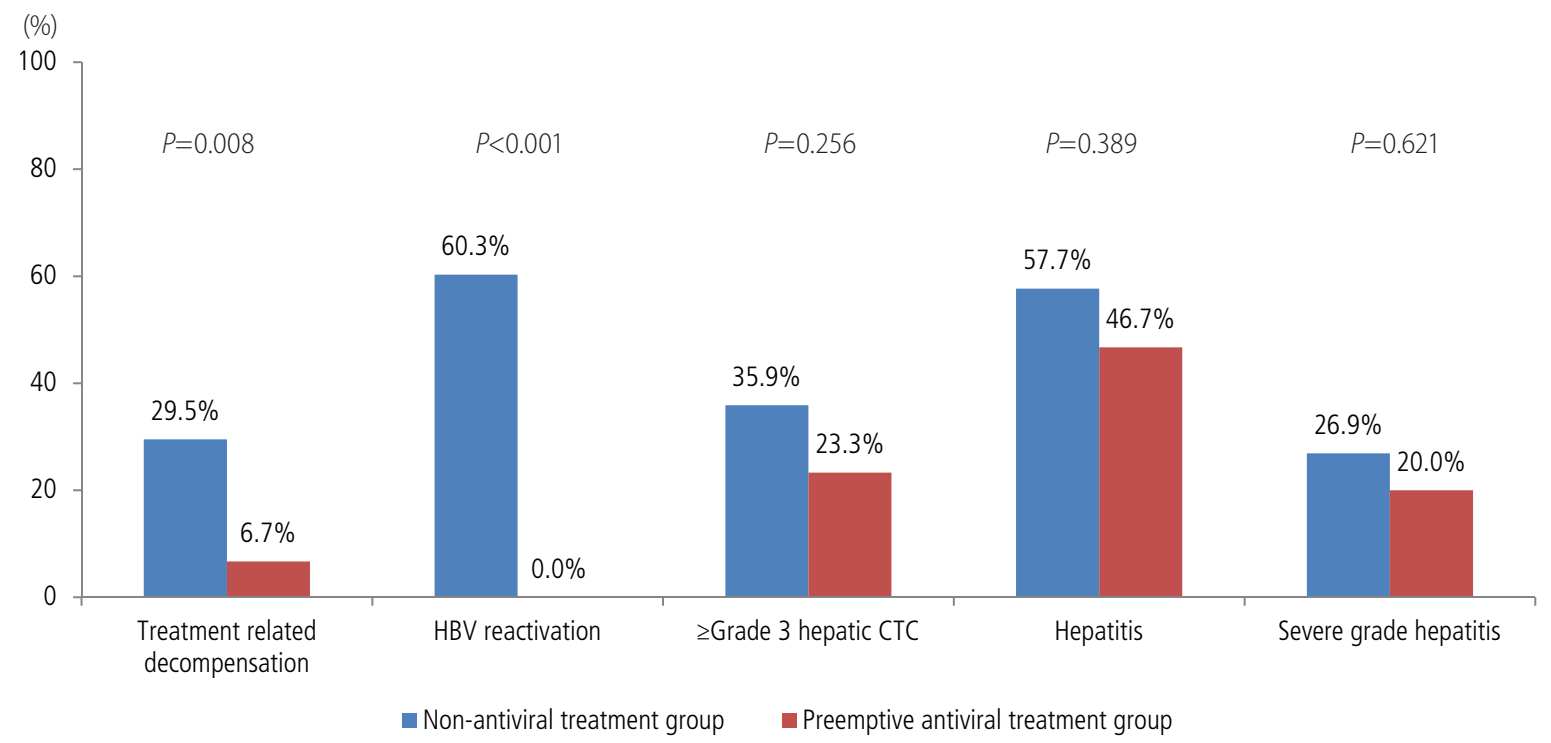

Figure 2. Comparison of hepatic events during TACE in patients with and without preemptive antiviral therapy. TACE, transarterial chemoembolization; HBV, hepatitis B virus; $\mathrm{CTC}$, common terminology criteria. 
Table 2. Univariate analysis of factors associated with treatment-related decompensation

\begin{tabular}{|c|c|c|}
\hline Parameters & HR $(95 \%$ Cl) & $\boldsymbol{P}$-value \\
\hline \multicolumn{3}{|c|}{ Gender (Female/Male) } \\
\hline Female & 1 & \\
\hline Male & $1.544(0.530-4.502)$ & 0.426 \\
\hline \multicolumn{3}{|l|}{ Age (years) } \\
\hline$\leq 55$ & 1 & \\
\hline$>55$ & $1.004(0.451-2.237)$ & 0.992 \\
\hline \multicolumn{3}{|l|}{$\mathrm{HBeAg}$} \\
\hline Negative & 1 & \\
\hline Positive & $0.637(0.266-1.526)$ & 0.312 \\
\hline \multicolumn{3}{|c|}{ HBV DNA (copies/mL) } \\
\hline$\leq 10^{5}$ & 1 & \\
\hline$>10^{5}$ & $1.506(0.675-3.361)$ & 0.318 \\
\hline \multicolumn{3}{|c|}{ Child-Pugh class } \\
\hline A & 1 & \\
\hline B & $1.907(0.821-4.427)$ & 0.133 \\
\hline \multicolumn{3}{|c|}{ Total bilirubin (mg/dL) } \\
\hline$<0.8$ & 1 & \\
\hline$\geq 0.8$ & $4.096(1.627-10.311)$ & 0.003 \\
\hline \multicolumn{3}{|l|}{$\mathrm{ALT}(\mathrm{IU} / \mathrm{L})$} \\
\hline \multicolumn{3}{|l|}{$<40$} \\
\hline$\geq 40$ & $1.297(0.591-2.848)$ & 0.516 \\
\hline \multicolumn{3}{|c|}{ Albumin (g/dL) } \\
\hline$>3.8$ & 1 & \\
\hline$\leq 3.8$ & $5.105(1.751-14.886)$ & 0.003 \\
\hline \multicolumn{3}{|c|}{ Creatinine (mg/dL) } \\
\hline$<0.8$ & 1 & \\
\hline$\geq 0.8$ & $0.698(0.317-1.534)$ & 0.370 \\
\hline \multicolumn{3}{|c|}{ Platelet $\left(\times 10^{3} / \mathrm{mm}^{3}\right)$} \\
\hline \multicolumn{3}{|l|}{$>120$} \\
\hline$\leq 120$ & $1.381(0.630-3.027)$ & 0.421 \\
\hline \multicolumn{3}{|l|}{ PT INR } \\
\hline$<1.1$ & 1 & \\
\hline$\geq 1.1$ & $1.590(0.700-3.614)$ & 0.268 \\
\hline \multicolumn{3}{|l|}{ AFP (ng/mL) } \\
\hline$<20$ & 1 & \\
\hline$\geq 20$ & $1.256(0.569-2.777)$ & 0.573 \\
\hline \multicolumn{3}{|c|}{ Total tumor size (cm) } \\
\hline$<5.0$ & 1 & \\
\hline$\geq 5.0$ & 1.609 (0.726-3.564) & 0.241 \\
\hline
\end{tabular}

Table 2. Continued

\begin{tabular}{|c|c|c|}
\hline Parameters & HR (95\% Cl) & $\boldsymbol{P}$-value \\
\hline \multicolumn{3}{|l|}{ Tumor number } \\
\hline Single & 1 & \\
\hline Multiple & $1.496(0.670-3.340)$ & 0.325 \\
\hline \multicolumn{3}{|l|}{ BCLC stage } \\
\hline A & 1 & \\
\hline B & $1.881(0.519-6.839)$ & 0.337 \\
\hline C & $2.597(0.729-9.244)$ & 0.141 \\
\hline \multicolumn{3}{|c|}{ Preemptive antiviral therapy } \\
\hline Preemptive & 1 & \\
\hline Non-preemptive & $4.550(1.072-19.306)$ & 0.040 \\
\hline \multicolumn{3}{|c|}{$\begin{array}{l}\text { Cox proportional hazards models. } \\
\text { HR, hazard ratio; } \mathrm{Cl} \text {, confidence interval; HBeAg, hepatitis B envelope } \\
\text { antigen; HBV DNA, hepatitis B virus deoxyribonucleic acid; ALT, alanine } \\
\text { aminotransferase; PT INR, prothrombin time international normalized ratio } \\
\text { AFP, alpha-fetoprotein; BCLC, Barcelona Clinic Liver Cancer. }\end{array}$} \\
\hline
\end{tabular}

patients (21.3\%) were BCLC stage 0,45 patients $(41.7 \%)$ were stage $A$, and 40 patients (37.0\%) were stage B. There were no significant differences in age, gender, HBeAg positivity, HBV DNA levels, total bilirubin, ALT, creatinine, $\alpha$-fetoprotein, total tumor size, Child-Pugh class, and BCLC stage of HCC between the two groups. However, patients in the preemptive group had significantly lower serum albumin levels ( $3.6 \mathrm{vs.} 3.8 \mathrm{mg} / \mathrm{dL}, P=0.036$ ) and platelet counts (102 vs. $136 \times 10^{3} / \mathrm{mm}^{3}, P=0.008$ ), and higher levels of PT INR (1.23 vs. 1.13, $P=0.008)$.

\section{Incidence of acute hepatic deterioration after TACE}

Among all 108 patients, 25 (23.1\%) suffered from treatment-related decompensation. The rate of decompensation was significantly lower in the preemptive group than in the non-preemptive group $(6.7 \%$ vs. $29.5 \%, P=0.008)$. HBV reactivation occurred more frequently in the non-preemptive group than in the preemptive group (60.3\% vs. $0.0 \%, P<0.001)$. Hepatic CTC for adverse events grade 3 or 4 , hepatitis, and severe-grade hepatitis following TACE developed in 35 (32.4\%), 59 (54.6\%), and 27 (25.0\%) patients, respectively. However, there were no significant differences in the hepatic CTC for adverse events grade 3 or 4 $(P=0.245)$, hepatitis $(P=0.317)$, and severe-grade hepatitis $(P=0.485)$ following TACE between the preemptive group and the non-preemptive group. Although the results revealed no significant statistical differences, the incidences of hepatic adverse events, hepatitis, and severe-grade hepatitis were lower in the preemptive group than in the non-preemptive group (Fig. 2). 


\section{Risk factors for treatment-related decompensation}

Treatment-related decompensation was observed in 25 patients (23.1\%); 3 patients developed ascites, 1 developed hepatic encephalopathy, 7 demonstrated an increase in bilirubin levels, and 21 demonstrated an increase in Child-Pugh score. Univariate analysis was performed to screen the risk factors for treatment-related decompensation (Table 2). The predictive factors included in the univariate analysis were gender, age, HBeAg positivity, HBV DNA levels, Child-Pugh class, total bilirubin, ALT, albumin, creatinine, platelet counts, PT INR, alpha-fetoprotein (AFP) levels, total tumor size, BCLC stage of $\mathrm{HCC}$, and preemptive antiviral therapy. Univariate analysis revealed that treatment-related decompensation was significantly associated with higher levels of total bilirubin $(\geq 0.8 \mathrm{mg} / \mathrm{dL}, P=0.003)$, lower levels of albumin $(\leq 3.8 \mathrm{~g} / \mathrm{dL}$, $P=0.003)$, and non-antiviral therapy $(P=0.040)$. In multivariate analysis, higher levels of total bilirubin $(\geq 0.8 \mathrm{mg} / \mathrm{dL}$; hazard ratio

Table 3. Multivariate analysis of factors associated with treatment-related decompensation

\begin{tabular}{lcc}
\hline Parameters & HR $(\mathbf{9 5} \% \mathbf{C l})$ & P-value \\
\hline Total bilirubin $(\mathrm{mg} / \mathrm{dL})$ & & \\
\hline$<0.8$ & $3.425(1.294-9.066)$ & 0.013 \\
$\geq 0.8$ & & \\
$\begin{array}{l}\text { Albumin }(\mathrm{g} / \mathrm{dL}) \\
>3.8\end{array}$ & $3.990(1.307-12.182)$ & 0.013 \\
\hline$\leq 3.8$ & & \\
\hline $\begin{array}{l}\text { Preemptive antiviral therapy } \\
\text { Preemptive }\end{array}$ & & \\
\hline Non-preemptive & & \\
\hline
\end{tabular}

Cox proportional hazards models.

$\mathrm{HR}$, hazard ratio; $\mathrm{Cl}$, confidence interval.
(HR), 3.425; 95\% Cl, 1.294-9.066; $P=0.013)$, lower levels of albumin ( $\leq 3.8 \mathrm{~g} / \mathrm{dL} ; \mathrm{HR}, 3.990 ; 95 \% \mathrm{Cl}, 1.307-12.182 ; P=0.015)$, and non-antiviral therapy (HR 7.597; $95 \% \mathrm{Cl}, 1.768-32.645$; $P=0.006)$ were the statistically significant factors predictive of treatment-related decompensation (Table 3). The cumulative incidence of treatment-related decompensation was significantly higher for patients with higher levels of total bilirubin $(\geq 0.8 \mathrm{mg} /$ $\mathrm{dL}, P=0.001$ ) or lower levels of albumin ( $\leq 3.8 \mathrm{~g} / \mathrm{dL}, P=0.001$ ) (Fig. $3 \mathrm{~A}, 3 \mathrm{~B})$. Patients who did not receive preemptive antiviral therapy had a higher risk of developing treatment-related decompensation than those who were given preemptive antiviral therapy $(P=0.024)$ (Fig. 3C).

\section{DISCUSSION}

Although TACE is one of the most effective treatments for HCC, repeated TACE can affect remnant hepatic function and interfere with the ability to continue treatment in patients with HCC. Furthermore, patients with HBV-related HCC can be affected not only by repeated TACE but also by hepatitis $B$ virus replication. This is because TACE is usually performed with administration of chemotherapeutic agents such as adriamycin or cisplatin. A prospective study showed that preemptive antiviral therapy in patients with $\mathrm{HBV}$-related HCC can reduce the incidence of hepatitis due to HBV reactivation during TACE. ${ }^{12}$

This study was conducted to evaluate the effect of preemptive antiviral therapy with entecavir on acute deterioration of hepatic function following TACE. One hundred eight patients with HBVrelated HCC treated with TACE were enrolled in this study. A comparison was made between 38 patients who received preemptive antiviral therapy with entecavir $(0.5 \mathrm{mg} /$ day $)$ and 70 patients who
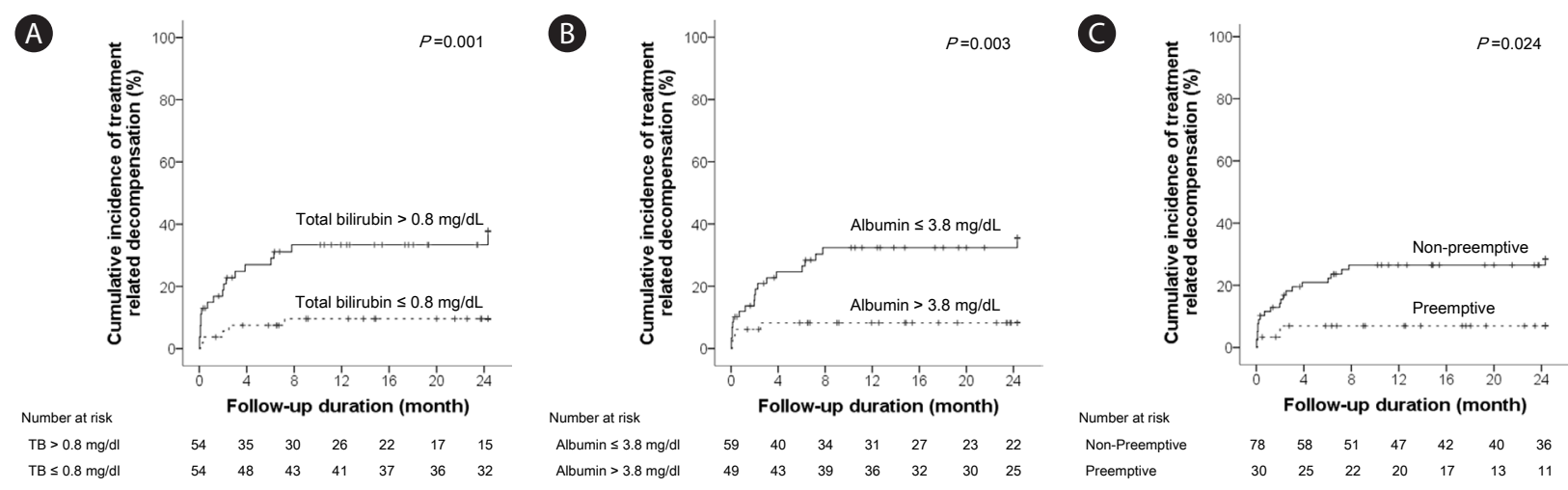

Figure 3. Differences in the cumulative incidence of treatment-related decompensation according to serum total bilirubin (A), serum albumin (B), and antiviral therapy (C). 
did not in terms of development of acute hepatic deterioration following TACE. This study is distinct from earlier studies in that all patients in the preemptive group received entecavir only, while patients in other studies received various antiviral agents, such as lamivudine, adefovir, dipivoxil, and telbivudine. ${ }^{19,20}$

In a retrospective study of 49 patients, Kuzuya et al. compared changes in remnant liver function after curative treatment for HCC according to whether patients received antiviral treatment or not. Remnant hepatic function was significantly better at the time of HCC recurrence in patients who received antiviral therapy. ${ }^{21}$ In addition to treating $\mathrm{HCC}$, nucleos(t)ide analogues can markedly inhibit acute deterioration of hepatic function after TACE. Lao et al. ${ }^{19}$ found that HBV reactivation after TACE was significantly reduced in patients who received antiviral therapy, and the rate of deterioration of liver function was higher in the HBV reactivation group than in the non-reactivation group. Another study showed that antiviral therapy with lamivudine can improve hepatic function and produce better outcomes after liver resection. ${ }^{22}$ In the present study, the cumulative incidence of treatment-related decompensation was found to be $23.1 \%$ in all patients. In our study population, the patients in the preemptive group started out with higher levels of serum HBV DNA and significantly worse markers of hepatic function, such as lower levels of albumin, lower platelet counts, and prolonged PT INR. Nevertheless, patients who received preemptive antiviral therapy showed a significantly lower incidence of TACE-related decompensation compared with the non-preemptive group (6.7\% vs. $29.5 \%, P=0.008)$.

Other studies proposed higher AFP, larger tumor size, and increased ALT levels as factors that influenced the development of complications or deterioration after TACE. ${ }^{10,19,23,24}$ However, in the present study, AFP, total tumor size, BCLC stage of HCC, and serum ALT levels had no significant effect on acute deterioration of liver function following TACE. Instead, higher serum total bilirubin and lower serum albumin levels significantly influenced treatmentrelated hepatic decompensation, as did not receiving preemptive antiviral therapy (Table 3).

We also analyzed the incidence of acute hepatic deterioration following TACE as well as the treatment-related decompensation. The incidence of acute hepatic deterioration, including hepatitis, severe hepatitis, and hepatic adverse events of grades 3 or 4 was greater in the non-preemptive group $(57.7 \%, 26.9 \%$, and $35.9 \%$, respectively) than in the preemptive group $(46.7 \%, 20.0 \%$, and $23.3 \%)$, although the difference was not statistically significant $(P=0.389, P=0.621$, and $P=0.256)$. The lack of statistical significance might be due to the small number of patients in the pre- emptive group rather than to a lack of effect of preemptive antiviral therapy.

The present study has several limitations. First, it was not a randomized controlled study. The study also lacked measures of longterm outcomes of HBV-related HCC treated with TACE. However, it is a post-hoc analysis from a database collected in a prospective manner. All patients received only TACE with a fixed dose of doxorubicin using the same technique in a single center, and patients in the preemptive group received entecavir only. The nature of this study population represents, therefore, a homogeneous and indicates that confounding factors behind management were significantly minimized. Reduction with antivirals in acute hepatic deterioration following TACE is likely to influence long-term clinical course. Future studies with larger numbers of patients and longer follow-up periods are necessary to further elucidate these findings.

In conclusion, our results demonstrated that preemptive antiviral therapy significantly reduces the risk of acute deterioration in hepatic function following TACE. Thus, preemptive antiviral therapy should be administered to patients undergoing TACE. Prevention of hepatic deterioration during TACE with such a preemptive approach may facilitate continuing anti-cancer therapy and thus potentially improve long-term outcomes

\section{Financial support}

This research was supported by Basic Science Research Program through the National Research Foundation of Korea (NRF) funded by the Ministry of Science, ICT \& Future Planning (NRF-2016R1D1A1B03930457).

\section{Acknowledgements}

The authors thank Dr. Won Sohn for his insightful and valuable comments during the preparation of this manuscript.

\section{Conflicts of Interest}

The authors have no conflicts to disclose.

\section{REFERENCES}

1. El-Serag HB. Hepatocellular carcinoma. N Engl J Med 2011;365:11181127.

2. Ikai I, Arii S, Ichida T, Okita K, Omata M, Kojiro M, et al. Report of the 16th follow-up survey of primary liver cancer. Hepatol Res 2005;32:163-172.

3. Bruix J, Sherman M. Management of hepatocellular carcinoma: an 
update. Hepatology 2011;53:1020-1022.

4. Lo CM, Ngan H, Tso WK, Liu CL, Lam CM, Poon RT, et al. Randomized controlled trial of transarterial lipiodol chemoembolization for unresectable hepatocellular carcinoma. Hepatology 2002;35:11641171.

5. Llovet JM, Real MI, Montaña X, Planas R, Coll S, Aponte J, et al. Arterial embolisation or chemoembolisation versus symptomatic treatment in patients with unresectable hepatocellular carcinoma: a randomised controlled trial. Lancet 2002;359:1734-1739.

6. Chung GE, Lee JH, Kim HY, Hwang SY, Kim JS, Chung JW, et al. Transarterial chemoembolization can be safely performed in patients with hepatocellular carcinoma invading the main portal vein and may improve the overall survival. Radiology 2011;258:627-634.

7. Luo J, Guo RP, Lai EC, Zhang YJ, Lau WY, Chen MS, et al. Transarterial chemoembolization for unresectable hepatocellular carcinoma with portal vein tumor thrombosis: a prospective comparative study. Ann Surg Oncol 2011;18:413-420.

8. Leng JJ, Xu YZ, Dong JH. Efficacy of transarterial chemoembolization for hepatocellular carcinoma with portal vein thrombosis: a metaanalysis. ANZ J Surg 2016;86:816-820.

9. Lee JM, Jang BK, Lee YJ, Choi WY, Choi SM, Chung WJ, et al. Survival outcomes of hepatic resection compared with transarterial chemoembolization or sorafenib for hepatocellular carcinoma with portal vein tumor thrombosis. Clin Mol Hepatol 2016;22:160-167.

10. Chan AO, Yuen MF, Hui CK, Tso WK, Lai CL. A prospective study regarding the complications of transcatheter intraarterial lipiodol chemoembolization in patients with hepatocellular carcinoma. Cancer 2002;94:1747-1752.

11. Liaw YF, Sung JJ, Chow WC, Farrell G, Lee CZ, Yuen H, et al. Lamivudine for patients with chronic hepatitis $B$ and advanced liver disease. N Engl J Med 2004;351:1521-1531.

12. Jang JW, Choi JY, Bae SH, Yoon SK, Chang UI, Kim CW, et al. A randomized controlled study of preemptive lamivudine in patients receiving transarterial chemo-lipiodolization. Hepatology 2006;43:233-240.

13. Sung PS, Bae SH, Jang JW, Song do S, Kim HY, Yoo SH, et al. Differences in the patterns and outcomes of enhanced viral replication between hepatitis C virus and hepatitis B virus in patients with hepatocellular carcinoma during transarterial chemolipiodolization. Korean J Hepatol 2011;17:299-306.
14. Jang JW, Kim YW, Lee SW, Kwon JH, Nam SW, Bae SH, et al. Reactivation of hepatitis $B$ virus in $\mathrm{HBsAg-negative} \mathrm{patients} \mathrm{with} \mathrm{hepato-}$ cellular carcinoma. PLoS One 2015;10:e0122041.

15. KASL clinical practice guidelines: management of chronic hepatitis $B$. Clin Mol Hepatol 2016;22:18-75.

16. Trinchet JC, Bourcier V, Chaffaut C, Ait Ahmed M, Allam S, Marcellin $\mathrm{P}$, et al. Complications and competing risks of death in compensated viral cirrhosis (ANRS C012 CirVir prospective cohort). Hepatology 2015;62:737-750.

17. Huang YS, Chiang JH, Wu JC, Chang FY, Lee SD. Risk of hepatic failure after transcatheter arterial chemoembolization for hepatocelIular carcinoma: predictive value of the monoethylglycinexylidide test. Am J Gastroenterol 2002;97:1223-1227.

18. U.S. Department of Health and Human services. Common terminology criteria for acverse events (CTCAE). In: National Institutes of Health, ed. National Cancer Institute, Vol. 4.03. 2010.

19. Lao XM, Luo G, Ye LT, Luo C, Shi M, Wang D, et al. Effects of antiviral therapy on hepatitis $B$ virus reactivation and liver function after resection or chemoembolization for hepatocellular carcinoma. Liver Int 2013;33:595-604.

20. Toyoda H, Kumada T, Tada T, Sone Y, Fujimori M. Transarterial chemoembolization for hepatitis B virus-associated hepatocellular carcinoma: improved survival after concomitant treatment with nucleoside analogues. J Vasc Interv Radiol 2012;23:317-322.

21. Kuzuya T, Katano Y, Kumada T, Toyoda H, Nakano I, Hirooka Y, et al. Efficacy of antiviral therapy with lamivudine after initial treatment for hepatitis B virus-related hepatocellular carcinoma. J Gastroenterol Hepatol 2007;22:1929-1935.

22. Li N, Lai EC, Shi J, Guo WX, Xue J, Huang B, et al. A comparative study of antiviral therapy after resection of hepatocellular carcinoma in the immune-active phase of hepatitis B virus infection. Ann Surg Oncol 2010;17:179-185.

23. Kohla MA, Abu Zeid MI, Al-Warraky M, Taha H, Gish RG. Predictors of hepatic decompensation after TACE for hepatocellular carcinoma. BMJ Open Gastroenterol 2015;2:e000032.

24. Siriwardana RC, Niriella MA, Dassanayake AS, Liyanage CA, Upasena $A$, Sirigampala $C$, et al. Factors affecting post-embolization fever and liver failure after trans-arterial chemo-embolization in a cohort without background infective hepatitis- a prospective analysis. BMC Gastroenterol 2015;15:96. 